\title{
MÚLTIPLAS FORMAS DE VIOLÊNCIA NA ESCOLA: notas sobre uma pesquisa em curso no IFPB, campus João Pessoa
}

\author{
MULTIPLE FORMS OF VIOLENCE AT SCHOOL: report from \\ ongoing research at IFPB, João Pessoa campus
}

\author{
Rita de Cássia Melo Santos* \\ Aline Toledo** \\ Selma Cabral ${ }^{* * *}$ \\ Adolfo Wagner ${ }^{* * * *}$
}

\begin{abstract}
Resumo
O presente artigo parte de uma experiência de pesquisa-ensino relacionada ao desenvolvimento do Programa Institucional de Bolsa de Iniciação à Docência (PIBID) da Universidade Federal da Paraíba (UFPB), no curso de Licenciatura em Ciências Sociais e no Instituto Federal da Paraíba (IFPB), Campus João Pessoa, no período de julho de 2018 a janeiro de 2020. A pesquisa centrou-se em identificar as múltiplas formas de violência existentes na unidade escolar, para isso realizando levantamento de dados junto aos setores institucionais de registro e resolução da violência, entrevistando psicólogos e docentes envolvidos com o combate e prevenção da violência na escola e, sobretudo, realizando investigações junto ao corpo estudantil por meio de grupos focais, entrevistas dirigidas e questionários. Neste artigo, pretendemos especificamente apresentar os resultados parciais obtidos a partir das manifestações de violência de gênero e LGBTQIfobia no IFPB/João Pessoa.
\end{abstract}

Palavras-chave: Violência Escolar; LGBTQIfobia; Violência de Gênero; Instituto Federal da Paraíba.

\footnotetext{
Abstract

This article is based on a teaching-research experience associated with the Teaching Initiation Scholarship Program (PIBID) in Social Science at the Federal University of Paraíba (UFPB) and at the Federal Institute of Paraíba (IFPB), João Pessoa Campus, during the period July 2018 to January 2020. The research focused on identifying the multiple forms of violence that exist in the school unit. For this purpose data surveys were conducted with the institutional sectors responsible for registering and resolving violence, as well as interviewing psychologists and teachers involved in combating and preventing violence at school and, above all, conducting investigations with the student body through

* Doutora em Antropologia Social (UFRJ/Brasil), professora adjunta do Departamento de Ciências Sociais/UFPB/Brasil. E-mail: santos.cm.rita@gmail.com.

** Aluna do Curso de Licenciatura em Ciências Sociais (UFPB/Brasil). E-mail: toledo_li@yahoo.com.br.

*** Aluna do Curso de Licenciatura em Ciências Sociais (UFPB/Brasil). E-mail: selminhacabral@ hotmail. com.

**** Professor do IFPB/Campus João Pessoa/Brasil. E-mail: adolfoifpb@gmail.com.
} 
focus groups, directed interviews and questionnaires. In this article, we specifically intend to present the partial results obtained relating to manifestations of gender violence and LGBTQIphobia at IFPB/João Pessoa.

Keywords: School Violence; LGBTQIphobia; Gender Violence; Federal Institute of Paraíba.

Introdução: de fora pra dentro, mudanças no campo do estudo da violência nas escolas

O presente artigo parte de uma experiência de pesquisa-ensino relacionada ao desenvolvimento do Programa Institucional de Bolsa de Iniciação à Docência (PIBID) da Universidade Federal da Paraíba (UFPB), no curso de Licenciatura em Ciências Sociais e no Instituto Federal da Paraíba (IFPB), Campus João Pessoa, no período de julho de 2018 a janeiro de 2020. O PIBID Sociologia UFPB/IFPB buscou ser um espaço de formação discente, pensando-se na formação de potenciais docentes de sociologia na educação básica, destinados à atuação na rede pública de ensino. Frente a isso, planejamos ao longo do período de vigência do projeto, a realização de múltiplas frentes de pesquisa, dentre as quais, o estudo da temática da violência na escola.

Essa temática é objeto de um campo de pesquisa com uma longa trajetória. Ele emerge nos anos de 1950 nos Estados Unidos, sendo pensado, sobretudo, a partir da utilização de armas de fogo, drogas e formação de gangues juvenis (ABRAMOVAY; RUA, 2002, p. 29). No caso do Brasil, essa tendência ao estudo da violência como fenômeno externo à escola, e associado à temática da juventude perigosa floresceu mais tardiamente, por meio dos estudos em relação ao entorno escolar e ao movimento das gangues (FACKIN, 2006). Centros urbanos como Rio de Janeiro e Porto Alegre foram privilegiados nesses estudos, notadamente o primeiro com os trabalhos de Alba Zaluar (ZALUAR, 1992; ZALUAR; LEAL, 1997, 2001).

A partir da década de 1980, a temática da violência nas escolas foi progressivamente mudando seu status da dimensão externa para pensar a sua dimensão institucional. Os estudos de Bourdieu e Passeron (1975) sobre a violência simbólica por parte da escola chamam atenção para uma dimensão mais múltipla acerca da violência $n a$ escola. Ela pode ser praticada também por aqueles que deveriam proteger e educar, e não envolve apenas o patrimônio e a dimensão física. Corroborando com essa postura, Hanke (1996) diz que focar nos atos criminosos extremados, como faziam os estudos na década 
de 1950, não colaborava com a compreensão sobre a natureza, a extensão e a associação entre violência e educação.

O debate avançou bastante ao longo das décadas seguintes na direção apontada pelos autores estrangeiros, aprofundando a compreensão da violência em sua dimensão simbólica e não apenas física. Autores brasileiros como Costa (1993), Rodrigues (1994), Guimarães (1995), Paim (1997), Cardia (1997), entre outros, têm desenvolvido importantes e criativos trabalhos nessa direção, apresentando-nos múltiplas nuances sobre o que estudantes, professores e comunidade escolar entendem como violência - seja patrimonial, física ou simbólica. A ênfase nessas três dimensões parecia ser o caminho por meio do qual os estudos sobre violência escolar floresceriam no Brasil na década seguinte. Contudo, um acontecimento dramático redirecionou, de modo fundamental, o debate sobre violência e juventude e, em consequência, violência e escola.

Em abril de 1997, cinco jovens assassinaram o indígena Pataxó Galdino Jesus dos Santos $^{1}$ no plano piloto de Brasília. O fatídico acontecimento deu início a uma série de investigações e publicações financiadas pela Unesco acerca da percepção dos jovens sobre a violência. O primeiro estudo publicado sobre o tema foi o trabalho de Waiselfisz (1998), que concluiu ser a violência entremeada ao tecido social e não apenas resultante da pobreza. O estudo inspirou a realização de outros trabalhos sobre juventude, escola e violência em outras capitais, como Rio de Janeiro, Curitiba e Fortaleza, respectivamente, produzidos por Souza (1999), Sallas et al. (1999) e Barreira (1999).

Ao final da primeira década do século XXI, outro evento fatídico marcaria mais uma inflexão nos estudos de violência e escola. Ocorrido em 2011, o que ficou conhecido como Massacre de Realengo, episódio no qual o jovem Wellington de Oliveira, na época com 23 anos, regressou armado à Escola Municipal Tasso da Silveira (situada em Realengo/RJ), da qual foi aluno, e assassinou 12 estudantes, em sua maioria meninas, na faixa etária de 13 a 15 anos. Em seguida, Wellington, rendido por um policial, cometeu suicídio. O episódio desencadeou a formação de várias associações de pais e uma série

\footnotetext{
${ }^{1}$ Galdino José dos Santos estava em Brasília em uma comitiva indígena para reivindicar seus direitos políticos e sociais. Os jovens atearam fogo em seu corpo enquanto o indígena dormia num ponto de ônibus. Questionados, disseram ter confundido o indígena com um mendigo. O caso gerou imensa comoção nacional.
} 
de ações, que culminaram em 2015 na promulgação da Lei do Bullying (Lei 13.185/2015), depois complementada pela Lei 13.663 de 2018 (BAZZO, 2018).

Ao Massacre de Realengo, primeiro episódio desse tipo no Brasil, somou-se outro evento ocorrido em 2019, o Massacre de Suzano. Praticado por dois estudantes, Guilherme Monteiro e Luiz Henrique Castro, o episódio ocorreu na Escola Estadual Professor Raul Brasil (situada em Suzano/SP). Na ocasião, os dois estudantes vitimaram dez pessoas. Ao contrário do ocorrido em Realengo, além de estudantes, foram mortos o tio de um dos agressores (assassinado em seu estabelecimento comercial), dois funcionários da escola (coordenadora e inspetora pedagógica) e os dois agressores (um foi assassinado pelo próprio companheiro, que em seguida cometeu suicídio).

Os oito anos que separam os dois eventos marcam também uma profunda ruptura na compreensão da escola e da violência no Brasil. Foi durante esse período que se aprofundou o debate sobre a Escola sem partido. Uma iniciativa inaugurada por Miguel Nagib, advogado e procurador do estado de São Paulo que, a partir de 2004, insta pais e estudantes a combater o que identificava como ideologia de gênero, formação de militantes e doutrinação ideológica. ${ }^{2}$ Embora iniciado em 2004, as ações do projeto se adensaram no início da década de 2010 quando o movimento organizou uma série de projetos de leis e de campanhas por todo país promovendo uma conversão sobre os significados do perigo nas escolas. Vimos ser produzida a figura do professor doutrinador, e esvaziado o debate acumulado sobre a violência nas últimas três décadas. A plataforma, que pretendia ser apartidária, foi utilizada nas últimas eleições de modo ostensivo, marcando a polaridade entre os defensores e os perpetradores da violência nas escolas. Acabou sendo descontinuada em agosto de 2019 devido à falta de apoio do presidente da República Jair Bolsonaro. ${ }^{3}$

É importante salientarmos essa nova perspectiva de compreensão da violência na escola, porque ela constituiu um lócus de retrocesso em relação às ações que estavam em curso. Como veremos, os dados obtidos com a nossa pesquisa continuam a sinalizar que

\footnotetext{
2 http://escolasempartido.org/quem-somos/.

${ }^{3}$ Miguel Nagib, criador do movimento Escola sem partido, requeria apoio político e econômico, não apenas do presidente, mas também de empresários e políticos. https://oglobo.globo.com/sociedade/edu cacao/escola-sem-partido-anuncia-suspensao-de-atividades-criador-do-movimento-desabafa-esperavam os-apoio-de-bolsonaro-23817368
} 
existe a permanência das múltiplas formas de violência na escola com a preponderância de casos de assédio moral e sexual, notificações de casos de racismo e de preconceito contra lésbicas, gays, bissexuais, transgêneros, queers e indiferentes (a quem nos referiremos, daqui para frente, como LGBTQI+). Há ainda um aspecto pouco documentado, que os estudantes denominam violência institucional. $\mathrm{O}$ debate promovido pelo movimento da Escola sem partido optou pela via de criminalização do debate sobre gênero e sexualidade nas escolas, contribuindo para o agravamento da situação. Entre as medidas propostas, havia a possibilidade de realização de denúncias anônimas contra os professores denominados “doutrinadores”. Embora não tenha logrado grande efetividade na implementação de sua agenda reformista, o movimento despertou a desconfiança com as políticas de ações afirmativas no âmbito do debate sobre gênero e sexualidade, assunto que apareceu em algumas falas dos estudantes entrevistados. Os dados preliminares, portanto, demonstram a importância de mantermos no espaço escolar, o debate sobre gênero, sexualidade e relações de poder, na contramão do preconizado por tendências do tipo da Escola sem partido.

Nesse sentido, o projeto desenvolvido pelos autores do artigo buscou desenvolver estratégias de observação, produção de dados e análises acerca das múltiplas formas de violência no Instituto. Tomando como pressuposto a definição de violência apresentada por Porto $(2015)^{4}$ como fruto de uma negação de alteridade. Interessava-nos saber, de modo mais concreto, o que era identificado pelos estudantes como violência. Como a escola estava reagindo e acolhendo os casos existentes? Quais categorias estavam sendo priorizadas nos registros e encaminhamentos? Quais eram os principais atores dos processos envolvidos? Para responder a essas questões e explicitar o caminho percorrido, dividimos o artigo em três partes. A primeira apresenta as experiência de estudos e mobilização em relação à violência existentes no IFPB, campus João Pessoa, e que nos auxiliaram a compreender o fenômeno na instituição. A segunda debruça-se sobre a condução do processo de pesquisa, narrando sobre os levantamentos e estratégias utilizadas. A terceira apresenta os dados obtidos com a pesquisa. Por fim, tecemos

\footnotetext{
4 “[...] haveria violência sempre que o outro fosse desconsiderado como sujeito e, em função disso, tratado como objeto, inviabilizando, em última instância, a interação social, seja ela de natureza consensual ou conflituosa. Violências poderiam, então, ser consideradas como negação da alteridade, lembrando que tal alteridade não se coloca em relação a um sujeito indefinido mas, ao contrário, face a alguém que tem cor, sexo, idade e, ao fazê-lo, põe em ação a sujeição criminal” (PORTO, 2015, p. 31-32).
} 
algumas considerações finais em que apontamos conclusões e caminhos possíveis para o desdobramento da experiência.

\section{Contextualizando a violência no IFPB/campus João Pessoa}

A preocupação com a violência já existia no IFPB antes da nossa chegada, especialmente no que concerne às questões de gênero e de identidade sexual. Quando iniciamos nosso trabalho no segundo semestre de 2018, havia no campus, um grupo (estudantes e docentes) plenamente mobilizado em torno da questão. Em outubro daquele ano, ocorreu a realização do $1^{\circ}$ Simpósio de Diversidade Sexual, de Gênero e Políticas de Igualdade, coordenado pelo grupo de Pesquisa Educação, Diversidade e Direitos humanos (atividade vinculada a um projeto de iniciação científica e extensão do Instituto). O evento foi composto por mesas de debates, oficinas temáticas e apresentações culturais, reunindo, principalmente, o público LGBTQI+ do campus, organizações culturais e artistas, além da presença de representantes dos governos municipal e estadual e de movimentos sociais. Após o encerramento do evento, ocorreu um encontro de avaliação e perspectiva para a realização do $2^{\circ}$ simpósio em 2019.

Além do simpósio, regularmente eram realizadas atividades tais como cinedebate, apresentações artísticas e rodas de diálogo. Essas ações buscavam integrar os grupos de pesquisa da instituição com a Coordenação de Direitos Humanos, professores de sociologia, núcleo pedagógico, Núcleo de Estudos e Pesquisas Afro-brasileiros e Indígenas (NEABI/IFPB), e estabelecer parcerias com instituições e espaços externos. Nessas ocasiões, notava-se a ausência do grêmio estudantil do IFPB. Demandados pelos por alguns professores do IFPB, o corpo discente articulou o grupo chamado "RESISTIR" - coletivo Yago Oliveira, ${ }^{5}$ organizado inicialmente por meio do aplicativo WhatsApp, e cujo foco voltava-se aos alunos LGBTQI+ do campus.

Até o encerramento das nossas atividades, realizamos uma reunião no pátio do IFPB com o coletivo Yago Oliveira e o Grupo de Pesquisa Educação Diversidade e Direitos Humanos - esse que havia feito levantamento no IFPB junto aos alunos sobre gênero, sexualidade, raça/etnia e diversidade religiosa para conhecer a situação dos

\footnotetext{
${ }^{5}$ Yago Oliveira foi um jovem paraibano que cometeu suicídio em março de 2018, motivado, conforme deixou escrito nas redes sociais, pelo preconceito e a discriminação que sofria por ser homossexual.
} 
estudantes na escola. Nós do PIBID/Sociologia nos propusemos a participar do projeto de pesquisa/extensão a partir de fevereiro de 2019, inserindo-nos no cine-debate e nas apresentações culturais. Porém, houve mudanças no projeto com a substituição de seus integrantes, e o coletivo Yago Oliveira não avançou, restringindo-se ao grupo virtual no WhatsApp. Em 2019, além do projeto já mencionado, outros dois entram em cena, um de pesquisa: "Os rumos da convivência no IFPB: Diversidade de gênero, sexual, étnicaracial e religiosa no Campus João Pessoa"; e outro de extensão: "Direitos Humanos e diversidade: formação de jovens na Escola Estadual Pedro Augusto Porto Caminha/Jaguaribe/JP (EEPAC)", ambos coordenados pela professora de sociologia do IFPB, Maria Suely Paula da Silva que já vinha atuando no tema.

Em parceria com a docente, realizamos oficinas temáticas para os alunos da EEPAC, oficinas de desenho, cinema e literatura (algumas delas relatadas em outros textos deste dossiê).

Sobre a história da mobilização dos estudantes em torno da temática "diversidade", identificamos a existência de alguns grupos no Instituto que não tiveram continuidade. Por exemplo, o grupo "Cor Carmim" era um coletivo de estudantes que contava com uma frequência média de 15 integrantes reunidos em torno da temática do combate à LGBTQIfobia. Atuou até meados de 2018, cujas principais ações voltavam-se para a publicização da temática, afixando material em paredes e murais do colégio, atuava também nas redes sociais (Facebook e Instagram) por meio do perfil @ coletivo.corcarmim. O motivo de sua descontinuação deveu-se à formatura de suas principais lideranças.

Em 2019, instalou-se no campus a "Rede de Combate ao Assédio" que atende exclusivamente estudantes, e possui um núcleo formado por servidores e alunos. Com o intuito de potencializar as ações até então desenvolvidas, a Rede funciona como um ponto de apoio e de aprofundamento das ações voltadas contra o assédio, desenvolvidas na Instituição. Cabe destacar que o IFPB conta com setores responsáveis pelo registro e encaminhamento de reclamações e denúncias, como o Departamento de Articulação Pedagógica (DEPAP), o Departamento da Assistência Estudantil (DAEST), a Coordenação de Assuntos Estudantis (CAEST) e a Ouvidoria. Espaços que nos forneceram dados sobre as múltiplas formas de violência no campus. 
Nossas primeiras investigações ocorreram no Departamento da Assistência Estudantil (DAEST). Em um primeiro momento, realizamos o levantamento nas fichas de notificação de ocorrências. Esse é o lugar onde os estudantes podem registrar suas insatisfações, problemas e ocorrências de modo geral. Em suma, o primeiro ponto de contato do corpo estudantil com a Instituição. Ao finalizar o levantamento, não foram constatados registros de casos de violência, seja do tipo referente à degradação do espaço físico, seja externa, como atuação de gangues e tráfico, ou ainda, algo de característica específica da escola (DEBARDIEUX, 1998). Em grande parte, os relatos se referiam ao comportamento dos estudantes no que diz respeito à ausência de uniforme escolar, uso de aparelhos sonoros, barulhos nos corredores e utilização do computador da sala de aula sem autorização. Todas essas ocorrências constituem infrações leves, conforme Regimento Interno do Instituto.

Em um segundo momento, direcionamo-nos à Coordenação de Assuntos Estudantis (CAEST) e à Ouvidoria do IFPB. Em ambos os casos, os resultados obtidos foram vagos e difusos. Sendo recorrente o registro de discriminação por meio da classificação de entrada do estudante no IFPB. Ser chamado de "estudante de quinta [chamada]" é considerado ofensivo, e alguns estudantes relataram o fato à CAEST. Para o registro do atendimento aos estudantes, é utilizado o Sistema Unificado de Administração Pública (SUAP), implementado há cerca de dois anos (o sistema ainda estava em aperfeiçoamento no período da pesquisa). Dentre as opções disponíveis para o atendimento há: "ansiedade; bullying; conflito com docente; conflito em sala de aula; conflito familiar; não identificação com o curso; orientação educacional; outros; programa/auxílios; violação de direitos." As dimensões da violência, objeto direto desta pesquisa, como assédio sexual, moral, furtos e/ou outros tipos de ocorrência, não tinham, à primeira vista, um registro direto. Isso não quer dizer, entretanto, que não ocorram, pois poderiam ser registrados na categoria "outros".

Em entrevista com a equipe operacional do SUAP, foi-nos informado que a maior recorrência versa sobre depressão, ansiedade, violência doméstica, estigmatização de transtornos e violência de gênero, essa última, destacadamente, presente no curso Técnico Integrado de Mecânica, no qual as poucas mulheres existentes são frequentemente 
hostilizadas. As queixas formais, feitas ao protocolo, são redirecionadas à CAEST catalogadas por temática.

No DEPAP, há o encaminhamento das denúncias relativas à relação professoraluno. Em geral, os estudantes iniciam o processo por um relato informal verbal, sendo no momento, orientados a formalizarem a denúncia. Ao fazê-lo, o DEPAP realiza reunião com o denunciante e com o professor separadamente, para colher a versão dos fatos de cada parte. Se o professor se mostra disposto a buscar uma resolução ao problema, fazse, então, uma reunião de conciliação entre os dois. Por outro lado, quando o professor se mostra inflexível, o caso é encaminhado ao setor de gestão de pessoas. Os casos relatados pela equipe do DEPAP versam desde a incompreensão mútua sobre a formação de grupos de trabalho, limite de horário para entrada em sala, desentendimentos quanto aos recursos de deslocamento dos estudantes, até a hostilidade e subestimação da capacidade feminina em cursos técnicos majoritariamente masculinos.

A análise preliminar dos órgãos e espaços destinados ao registro e resolução de episódios de violência aponta para a existência de uma equipe profissional comprometida com a temática, mas que dispõe ainda de poucos recursos técnicos para a sua operacionalização e realização, a começar pelo próprio sistema informático utilizado (SUAP), que, por exemplo, deixa em segundo plano as notificações de assédio sexual, aspectos fundamentais e graves são perdidos em uma categoria difusa: "outros". A intenção da nossa pesquisa, portanto, de verificar com especial ênfase as múltiplas formas de violência de gênero e LGBTQI+ se mostrou urgente e partimos para a escuta direta dos estudantes.

\section{Em busca dos dados}

Em virtude da ausência de dados nos órgãos supracitados, iniciamos uma investida de escuta e observação pelo campus. Nos cine-debates, nas oficinas e no acompanhamento das aulas permanecemos atentos às reclamações e insatisfações manifestas dos estudantes com a Instituição, colegas, professores e funcionários. A partir do diário de campo, fomos anotando e sistematizando o que parecia ser as reclamações mais frequentes - as "piadas" de professores e técnicos acerca das vestimentas das meninas, os elogios que ultrapassavam a cordialidade, as insinuações de pouca 
capacidade intelectual das meninas, os usos dos espaços de circulação no campus quanto ao gênero, a cobrança desigual pelo uso do uniforme escolar ${ }^{6}$, foram alguns dos aspectos observados.

A partir da sistematização dos pontos recorrentemente indicados pelos estudantes, montamos um roteiro com 14 questões (quadro a seguir) para serem desenvolvidas por meio de grupos focais, coordenados pela equipe no turno da manhã e da tarde, e contou com a participação de 18 estudantes do ensino médio integrado IFPB em cada turno. Durante 2 horas, os estudantes relataram e debateram suas experiências em relação ao tema. Nos relatos aparecem a discriminação e violência simbólica praticadas por funcionários e professores, destacando-se algum tipo de agressão verbal e determinadas "brincadeiras" de teor sexual ou relacionado à diversidade de gêneros. Os alunos se sentem ofendidos e constrangidos, e ao mesmo tempo desamparados, sem saberem a quem recorrer, com medo da autoridade e com receio da impunidade, pois os agressores, por serem servidores públicos concursados, "não sofreriam sanções".

Quadro: Questões aplicadas aos alunos reunidos nos grupos focais

* O que vocês entendem por violências?

* E a violência na escola, o que seria?

* Alguém aqui já sofreu violência no espaço escolar?

* De que tipo?

* Quem pratica a violência na escola?

* Em quais circunstâncias?

* Alguém já se sentiu desconfortável na escola? Por quais razões?

* O que é bullying?

* O bullying é um tipo de violência?

* Vocês já souberem ou presenciaram algum tipo de assédio (moral e/ou sexual) na escola?

* Já presenciaram discriminação com base em critérios raciais, de gênero, de orientação sexual ou de condição étnica e/ou social?

* Algum bem seu já foi subtraído nas dependências da escola?

* Como se dá o convívio no âmbito geral da escola?

* E especificamente em relação aos espaços e vestimentas.

\footnotetext{
${ }^{6} \mathrm{O}$ IFPB congrega cursos de nível superior e médio técnico. O uso de uniforme e o cumprimento rigoroso do horário são exigências apenas para os estudantes do nível médio, o que gera muita insatisfação por parte deles.
} 
Para a composição de cada grupo focal (composto por 4 a 10 pessoas) levamos em consideração o perfil dos cursos quanto ao gênero (mais ou menos masculinos); raça; orientação sexual; idade e gênero. Buscamos montar os grupos proporcionalmente à diversidade do corpo discente. Estabelecemos como orientações de funcionamento do grupo focal: “a) uma pessoa fala de cada vez; b) evitam-se discussões paralelas para que todos participem; c) ninguém pode dominar a discussão; d) todos tem o direito de dizer o que pensam.” Essas orientações foram apresentadas no início da reunião. Além disso, distribuímos papel e caneta aos estudantes, com a solicitação de que registrassem suas ideias e sensações sem interromper o momento de fala dos demais colegas. Quando havia silêncio, estimulávamos a livre expressão dos estudantes sem, contudo, focar em uma única pessoa. Buscávamos estabelecer um clima geral de acolhimento e compartilhamento comum de experiências a fim de minimizar o impacto de possíveis ocorrências de gatilhos emocionais. Também pretendíamos realizar um grupo focal reunindo técnicos e docentes, funcionários da limpeza e agentes de segurança sobre a mesma temática. Contudo, a indisponibilidade de tempo e as escalas de trabalho impossibilitaram sua ocorrência.

Após a realização dos grupos focais, passamos à elaboração de um questionário com os pontos desenvolvidos e confirmados pelos grupos. Composto por quatro partes, ele inquiria sobre: 1) e-mail; 2) informações gerais (gênero, sexo, idade, residência etc.); 3) perfil socioeconômico (se recebia algum tipo de auxílio, renda média familiar, tipo de residência, atividade remunerada, domínio de línguas estrangeiras, escolaridade dos pais, tempo de deslocamento para o IFPB etc.); e 4) informações acerca da violência (se já havia sofrido algum tipo de violência no Instituto, tipologia da violência, agente da violência, vivência de bullying no Instituto, ocorrência de violência doméstica, identificação da rede de apoio no IFPB etc.).

O roteiro do questionário foi discutido com a equipe do PIBID, buscando cobrir os diferentes tipos de violência existentes, desde o seu domínio estrutural, passando por aspectos sistêmicos até o âmbito doméstico (MALDONADO, 1997). Em um estudo com escolas na grande São Paulo, Fante chegou a impressionantes números: dos 1.761 estudantes entrevistados, $49 \%$ estavam envolvidos com violência na escola, notadamente, relacionada ao bullying. Desses, 22\% eram vítimas, $15 \%$ agressores, e $12 \%$ vítimas- 
agressores (FANTE, 2005). Estes resultados nos põem em alerta, no sentido de compreender os dados da nossa investigação desde uma perspectiva mais complexa, procurando compreender o fenômeno como um todo, ou seja, que imbrica as vítimas aos seus perpetradores, e, em alguns casos, coincidindo os papéis.

\section{Algumas observações sobre resultados preliminares}

Uma das coisas que mais nos chamou a atenção no acompanhamento das aulas de sociologia e dos grupos focais, foram as associações realizadas pelos jovens entre o que vivem e questões maiores ou gerais. Expressam e articulam muito bem ideias e sentimentos. Sentem muito a falta de um ambiente apropriado para descanso e alimentação, visto que a maioria dos cursos do técnico integrado ao médio ocorrem no período da manhã e da tarde. O restaurante universitário não fornece alimentação, servindo apenas de espaço para refeições, e não existe local para descanso. É parte da rotina do campus encontrar estudantes sentados pelos corredores, algumas vezes, ali se alimentando, o que, conforme relataram, gera discussões com funcionários, que são orientados a impedi-los de utilizarem aquele espaço para esse fim. Os estudantes se sentem muito pressionados com as provas e notas, inclusive porque estas estão associadas aos auxílios, e a sua perda pode significar a saída da escola.

Reconhecem o Instituto como uma boa escola, estando acima da média, tanto de escolas públicas quanto privadas, no sentido de infraestrutura e ensino. O fato de oferecer também o ensino superior é apontado como fator de diferença no ambiente. A psicóloga e a assistente social entrevistadas afirmaram que existe um ambiente mais livre no Instituto, o que permite maior expressão cultural e de comportamento. Em um dos grupos focais, essa questão foi tocada: os estudantes afirmaram que o bullying era muito presente na escola privada onde estudaram, decorrente da padronização demasiada, no sentido de predominância de pessoas da mesma classe social. No Instituto, segundo eles, existe uma convivência maior com a diversidade, o que permite ampliação de experiências. Os casos de violência apontados são frequentemente associados à própria Instituição. Aqueles caracterizados como bullying são tratados, por ela, de modo bastante secundário.

A fala de um dos participantes do grupo focal exemplifica sua visão da violência:

Entrar no espaço do outro seja fisicamente seja moralmente. Então, quando me vem violência em mente eu penso em violar, invadir. Porque, geralmente, 
quando a gente pensa em violência pode vir em mente logo a violência física; e a moral, às vezes, tem o mesmo patamar da física, uma violência psicológica, moral que não afeta fisicamente, mas pode afetar tanto quanto (estudante 01). ${ }^{7}$

Nos grupos focais, apareceram, mais abertamente, as questões de assédio contra as meninas. Elas relataram terem sofrido assédio, principalmente, por parte dos professores, no qual predominam as insinuações de cunho sexual. Relataram também "assobios" e "olhares" que as intimidam, fazendo com que mudem seus trajetos para evitar o assédio. Os meninos também relataram serem estimulados, inclusive por professores, a realizarem este tipo de prática, fazer comentários de cunho sexual, e estar em determinados lugares que permitem observar melhor as partes do corpo das meninas. É possível observar que existe uma reprodução da opressão contra as mulheres no âmbito escolar, colocando-as em situação de vulnerabilidade e ameaça. As estudantes destacaram também que sentem insegurança no trajeto casa-escola, onde estão sujeitas à ameaça de violência sexual.

As falas abaixo exemplificam situações nas quais a violência se manifesta:

Aqui na instituição é como a gente recebe, pelo menos eu já recebi assédio de professores e servidores. Olhares que me deixam em uma situação de total constrangimento. Para mim, isso é me violar, então eu tenho medo de colocar uma roupa mais curta, enfim. Algo que a gente vive diariamente e a gente não fala, a gente coloca essa situação como se fosse habitual e normal, quando não deve ser (estudante 02).

Outro caso também foi na minha sala que eu relatei, foi um tipo de discriminação por orientação sexual, mas eu fiquei muito triste realmente. Me desculpa a palavra porque é uma coisa muito escrota. Eu perguntar para o professor quantas pessoas era para formar o grupo, e o professor respondeu "eu sei que você gosta de ficar de quatro, mas o trabalho é de cinco" (estudante 03).

Uma das psicólogas do campus apontou questões de relacionamento entre professores e estudantes no sentido do ensino, como a intolerância com atrasos. Não considerou questões mais particulares dos alunos que rebatem em problemas com notas e na possibilidade de evasão escolar, por não conseguirem cumprir os prazos institucionais das avaliações. A assistente social entrevistada também relatou problemas com o acompanhamento do curso e em dar apoio aos estudantes nesses casos. Em nenhuma das conversas apareceu denúncia de assédio sexual propriamente dito, ao contrário do que foi colocado nos grupos focais. Entendemos que a diferença entre as

\footnotetext{
${ }^{7}$ Não apresentamos nomes pessois para reservar a identidade dos participantes. As idades variam entre 15 a 17 anos.
} 
colocações de servidoras e técnicas e o observado nos grupos focais, deve-se ao direcionamento de cada espaço. Quando se dirigem aos setores escolares, os estudantes defrontam-se com servidores e um sistema que organiza e sistematiza denúncias específicas. Denúncias essas, como vimos, que não contemplam diretamente e prioritariamente a questão do assédio. Para a realização do grupo focal, esclarecemos, desde o princípio, o nosso interesse, e isso, claro, constituiu um espaço propício à fala. Como aponta Pollak (1989), para dizer é preciso ser estabelecido um ambiente propício e destinado à escuta. Do contrário, impera o silêncio e, com ele, o esquecimento.

Outro ponto, levantado nos grupos focais, foram o desprezo e subestimação por parte dos professores da capacidade e opinião das meninas. Há a recorrência de relatos em que professores priorizam as experiências em laboratório para os meninos com a justificativa de que as meninas não conseguiriam executar a tarefa sozinhas.

Os alunos revelam que a LGBTQIfobia se reflete dentro da escola, demonstrando receio de serem vítimas da prática da violência de gênero e sexualidade dentro do campus, e no trajeto casa-escola. Algumas alunas adotam práticas preventivas, como evitar o uso de determinadas roupas que poderiam despertar o assédio no trajeto, como podemos ver na fala abaixo:

Tem dia que, às vezes, eu vou de ônibus para casa e eu troco minha roupa, porque eu saio da educação física e estou de short. Já aconteceu de eu e uma colega minha trocar o short por calça por que a gente vai de ônibus e tal, e muitas vezes o ônibus está cheio, e sabe, fica perto e tal, e já aconteceu no ônibus que eu estava sentada e aí tinha um cara ele estava bem do lado se encostando. É terrível a forma (estudante 04).

Como desenvolvem uma rotina de atividades durante todo o dia no campus considerado uma extensão das suas casas —, os alunos relatam que a Instituição não possui estrutura adequada para atender suas necessidades, como é o caso dos banheiros que não oferecem nem privacidade e nem segurança. Relataram que havia um banheiro "unissex", usado por pessoas LGBTQI's, porém, acabou sendo desativado em decorrência de discriminação/preconceito dirigidos às pessoas que o utilizavam. De modo geral, os casos de violência relatados nos grupos focais apontam para o assédio sexual e moral, principalmente em relação ao gênero, como também, discriminação de gênero, sexualidade, racial, e religiosa no âmbito escolar. Apesar do combate ao racismo, alguns 
tipos de violência, como a transfobia e a LGBTQIfobia aparecem menos discutidas no âmbito do IFPB. É o que aponta a fala a seguir:

Uma professora passando um vídeo sobre racismo para combater o racismo, e tem estudantes praticando outro tipo de violência que é a homofobia, muita gente não sabe que a homofobia virou crime no país (estudante 05 ).

Abramovay e Rua (2002) destacam que, nos casos de violência sexual que acontecem nas escolas, as meninas são as principais vítimas, sendo os agressores, algumas vezes, seus colegas, outras vezes, os professores. Essas atitudes seriam incorporadas ao conceito de violência simbólica e são parte de uma violência moral reproduzida e ignorada pelas escolas. É um enfrentamento entre os sexos com marca de abuso de poder.

A partir dos questionários, fizemos o seguinte levantamento: 39,7\% dos participantes da pesquisa disseram ter sofrido algum tipo de violência no Instituto, e desses, 33,3\% foram vítimas de assédio sexual, e 56,7\% de assédio moral, o que pode incluir o assédio por gênero. Entre os agentes da violência, 56,3\% são outros estudantes, e $43,7 \%$ são professores.

Outro aspecto bem marcado nas falas das meninas, já destacado, foi a insegurança no trajeto casa-escola com a ameaça de violência sexual. 58,1\% declararam essa insegurança, das quais 48,8\% expressam medo de sofrer assédio sexual.

Devido às paralisações escolares, como greve e férias (do IFPB e da UFPB), não conseguimos aplicar o número previsto de questionários, ${ }^{8}$ alcançamos apenas 79 alunos. Por não considerarmos essa amostra representativa da Instituição, optamos por não realizar a análise completa dos dados, pretendendo fazê-la em outro momento. Contudo, acreditamos, pela análise preliminar, que o quadro a ser construído reiterará os dados apresentados por Abramovay e Rua (2002).

\section{Algumas considerações finais}

A violência foi estruturante para as identidades coletivas no Brasil, é motivo que mobilizou a luta, gerando os movimentos de mulheres, negros e LGBTQI+, visibilizando tipos específicos de violência, (violência de gênero, racismo, LGBTQIfobia etc.),

\footnotetext{
${ }^{8}$ Estimávamos a aplicação de 625 questionários para uma margem de erro de $4 \%$ nos resultados obtidos.
} 
reivindicando criação das delegacias especializadas de atendimento à mulher e de leis que criminalizam a violência doméstica, o feminicídio, o racismo e a LGBTQIfobia. A produção de bancos de dados e estatísticas foram essenciais para registrar os assassinatos de mulheres e LGBTQI+. A partir dos anos 80, por exemplo, o grupo Gay da Bahia passou a elaborar dossiês dos assassinatos de LGBTQI+ no país.

A partir daí, temos a multiplicação de pesquisas na área das ciências humanas e sociais de temas relacionados à homossexualidade e gênero. A divulgação de relatórios com os casos de assassinatos de LGBTQI+ contribuiu para estabelecer propriedades da agenda do movimento e a denúncia da violência contra esses grupos. Os dados também revelam, no cotidiano, outros casos de denúncias de ofensas, ameaças, extorsões, agressões físicas e queixa de discriminação na escola, no trabalho, no comércio e família, enfatizando que a violência que atinge LGBTQI+ é heterogênea e complexa, indo além do modelo clássicos do crime de ódio.

O programa "Brasil sem homofobia"9 lançado em 2004, reconhece a especificidade e a diversidade de formas de violência que atingem a população LGBTQI+. Ele prevê um conjunto bastante amplo de ações, com destaque para a política para mulheres lésbicas e a articulação do combate ao racismo. A LGBTQIfobia opera com variáveis que vão desde a discriminação na esfera doméstica a crimes com fins de lucro, com isso, as estratégias de enfrentamento têm que reconhecer essa complexidade e mobilizar demandas específicas para diferentes formas de violência. Em relação à criminalização da LGBTQIfobia, em 2019, o Supremo Tribunal Federal (STF) determinou que a discriminação por orientação sexual e identidade de gênero passasse a ser considerada crime, sendo punida pela Lei de Racismo (7.716/89), que hoje prevê crimes de discriminação ou preconceito por "raça, cor, etnia, religião e procedência nacional". Os casos de LGBTQIfobia registrados na escola, indicam a necessidade de pesquisas e da criação de programas envolvendo autoridades educacionais, professores e alunos voltados para a questão.

O diálogo sobre gênero e sexualidade no IFPB torna-se essencial para analisar a posição sociocultural dessa Instituição na reprodução da heteronormatividade, e a

\footnotetext{
${ }^{9}$ Programa do Ministério da Saúde de combate à violência e à discriminação contra GLTB e de promoção da cidadania homossexual. Ver: ttps://bvsms.saude.gov.br/bvs/publicacoes/brasil_sem_homofobia.pdf.
} 
transformação de suas práticas e discursos para o convívio justo com as diferenças e pluralidade, eliminando a LGBTQIfobia do seu cotidiano.

Conforme Berenice Bento (2011), numa sociedade com normas de gênero e valores hegemônicos, que articula gênero e sexualidade na reprodução social dos corpos, reproduzindo corpos "normais" e silenciando/excluindo outros, numa perspectiva binária masculino e feminino com sua complementação heterossexual, encontra no espaço da escola terreno fértil de disseminação. Nesse sentido, a produção das identidades de gênero é marcada por uma profunda violência e desconsidera que a humanidade se organiza e se estrutura na e pela diferença. Os dados levantados nesta pesquisa revelam que a LGBTQIfobia do contexto da sociedade reflete-se dentro da escola. Assim, enfatizamos a importância do debate sobre gênero e sexualidade na escola, do ensino da sociologia e da participação de toda a comunidade escolar no enfrentamento das diversas formas de violência que nela se manifestam.

\section{Referências}

ABRAMOVAY, M.; RUA, M. G. Violências nas escolas. Brasília: UNESCO, Instituto Ayrton Senna; UNAIDS; Banco Mundial; USAID; Fundação Ford; CONSED; UNDIME, 2002.

BARREIRA, C. et al. Ligado na galera: juventude, violência e cidadania na cidade de Fortaleza. Brasília: UNESCO; Instituto Ayrton Senna; UNICEF; FNUAP, 1999.

BAZZO, J. “Agora tudo é bullying": uma mirada antropológica sobre a agência de uma categoria de acusação no cotidiano brasileiro. 2018. Tese (Doutorado em Antropologia Social) - Instituto de Filosofia e Ciências Humanas, Programa de Pós-Graduação em Antropologia Social, Universidade Federal do Rio Grande do Sul, Porto Alegre, 2018.

BENTO, B. Na escola se aprende que a diferença faz a diferença. Estudos feministas, Florianópolis, v. 19, n. 2, p.548-559, 2011. Disponível em: https://www.scielo.br/ scielo.php?pid=S0104-026X2011000200016\&script=sci_abstract\&tlng=pt. Acesso em: 07/05/20.

BOURDIEU, P.; PASSERON, J. A reprodução: elementos para uma teoria do sistema de ensino. Rio de Janeiro: Francisco Alves, 1975.

CARDIA, Nanci. A violência urbana e a escola. Contemporaneidade e Educação. Rio de Janeiro, IEC, ano 2, n.2, p. 26-69, 1997.

COSTA, Eloísa Helena de Campos. A trama da violência na escola. 1993. Dissertação (Mestrado em Educação) - Instituto de Estudos Avançados em Educação, Fundação Getúlio Vargas, Rio de Janeiro, 1993. 
DEBARBIEUX, E. et al. La violence à l'école: approaches européenes. Revue Française de Pédagogie, Lyon, n. 123, p. 7-19, 1998. Disponível em: https://www. persee.fr/doc/rfp_0556-7807_1998_num_123_1_1123. Acesso em: 07/05/20.

FACKIN, Rosemari. Violência na escola, da escola, e no entorno da escola. Cadernos de Pós-Graduação, São Paulo, v. 5, n. 1, p. 75-82, 2006. Disponível em: https:// periodicos.uninove.br/index.php?journal=cadernosdepos\&page $=$ article \&op $=v i e w \&$ path $\% 5 \mathrm{~B} \% 5 \mathrm{D}=1847 \&$ path $\% 5 \mathrm{~B} \% 5 \mathrm{D}=1446$. Acesso em: 07/05/20.

FANTE, C A. Z. Fenômeno "bullying": como prevenir a violência nas escolas e educar para a paz. Campinas: Verus, 2005.

GUIMARÃES, M. E. Escola, galeras e narcotráfico. 1995. Tese (Doutorado em Educação) - Pontifícia Universidade Católica do Rio de Janeiro, Rio de Janeiro, 1995.

HANKE, P.J. Putting school crime into perspective: self-reported school victimizations of high school seniors. Journal of Criminal Justice, Iowa/EUA, v. 24, n. 3, p. 207-226, 1996. Disponível em: https://www.sciencedirect.com/science/article/pii/004723529600 0062. Acesso em: 07/05/20.

MALDONADO, M. T. Os construtores da paz: caminhos da prevenção da violência. São Paulo: Moderna, 1997.

PAIM, I. M. As representações e a prática da violência no espaço escolar. 1997. Dissertação (Mestrado em Educação) - Universidade Federal Fluminense, Niterói, 1997.

POLLAK, M. Memória, esquecimento e silêncio. Estudos Históricos, Rio de Janeiro, v. 2, n. 3, p. 3-15, 1989.

PORTO, M. S. G. A violência, entre práticas e representações sociais: uma trajetória de pesquisa. Sociedade e Estado, Brasília, v. 30, n.1, p. 19-37, 2015. Disponível em: https://www.scielo.br/pdf/se/v30n1/0102-6992-se-30-01-00019.pdf. Acesso em: 07/05/20.

RODRIGUES, A. S. Aqui não há violência: a escola silenciada (Um estudo etnográfico). 1994. Dissertação (Mestrado em Educação) - Pontifícia Universidade Católica do Rio de Janeiro, Rio de Janeiro, 1994.

SALLAS, A. L. F. et al. Os jovens de Curitiba: esperanças e desencantos, juventude, violência e cidadania. Brasília: UNESCO, 1999.

SOUZA, M. C. de et al. Fala galera: juventude, violência e cidadania na cidade do Rio de Janeiro. Rio de Janeiro: UNESCO; Instituto Ayrton Senna; Fundação Ford; Fiocruz; Editora Garamond, 1999.

WAISELFISZ. J. J. Juventude, violência e cidadania: os jovens de Brasília. São Paulo: Cortez, 1998.

ZALUAR, A. (Org.) Violência e educação. São Paulo: Cortez, 1992.

ZALUAR, A.; LEAL, M. C. Gênero e educação pública: uma comparação entre o CIEP e a escola comum. Revista Brasileira de Estudos Pedagógicos. Brasília, v. 78, n. 188/189/190, p. 157-194, 1997. 
ZALUAR, A.; LEAL, M. C. Violência extra e intramuros. Revista Brasileira de Ciências Sociais, São Paulo, v. 16, n. 45, p. 145-164, 2001. Disponível em: https://www.scielo.br/scielo.php?script=sci_arttext\&pid=S0102-69092001000100008\& $\operatorname{lng}=$ pt\&nrm=iso\&tlng=pt. Acesso em: 07/05/20.

Recebido em: 25/03/20.

Aceito em: 07/05/20. 